\title{
SOCIAL ROLES AND PSYCHOLOGICAL CONTINUITY: A CONFUCIAN-PSYCHOLOGICAL CONTINUITY HYBRID ACCOUNT OF PERSONAL IDENTITYAND ONTOLOGY
}

\author{
SAMMUEL BYER
}

\begin{abstract}
In this paper, I delineate a variety of questions related to personal identity and ontology. I develop and compare the Confucian conception of the person and the view of the person developed throughout Derek Parfit's work on personal identity and ontology. I will demonstrate that the Confucian conception of the person has numerous instructive similarities with Parfit's work on personal identity, despite a number of differences. I argue, briefly, that this project is worthwhile as a piece of comparative philosophy. One of the final two sections of the paper develop a new hybrid account of personal identity and ontology that combine the Confucian and Parfitian views of personal identity and personal ontology. The last section of the paper goes into detail developing this view in response to potential questions, and responds to some objections to this hybrid account, including objections based on a similarity between the Confucian account and the narrative account of personal identity.
\end{abstract}

Keywords: Confucian, Kong Zi (Confucius), narrative theory of personal identity, Parfit, personal identity, personal ontology, psychological continuity, role-persons, the self

\section{INTRODUCTION}

Personal identity is a messy topic in philosophy. This messiness is due to the many ways that the concept is used. It is of central importance for most human endeavors to have some answer to the question "What is a person?" This is a question about what sort of thing persons are - a specific kind of object or substance, say, or a process, or a set, or a composite of objects, substances, processes, or sets. Call this the question of personal ontology.

In Western philosophical traditions, nearly every answer to this prior question also gives us some answer to the following question "If a person is the same, in virtue of what feature are they the same?" In other words, what features must remain the same in order for some person at time $t_{1}$ to be identical to some person at time $t_{2}$ ? Even the

BYER, SAMMUEL R.: Assistant Professor of Philosophy, Fort Hays State University, USA. Email: srbyer@fhsu.edu 
concept of identity involved in this question needs further clarification. Usually, theorists mean to hold views about numerical identity as opposed to qualitative identity. The question of numerical identity is whether a given entity is exactly one-and-thesame entity. The question of qualitative identity is whether an entity is the same qualitatively, but not literally, exactly, or numerically. As an example, the shirt I am wearing will be the same shirt even if it loses some qualitative properties (e.g. if it is bleached and changes color, or becomes worn and gets a hole in it, or the tactile sensations it gives rise to change after several washings). On the other hand, if I purchased two shirts that are identical, they would be qualitatively identical insofar as they would have all of the same qualitative features (e.g. made of the same material, being the same size and shape, being the same color, having the same level of softness, sporting the same design on the left breast pocket, etc), despite the fact that they are clearly not the same object. Further complicating this issue is whether the identity sought is diachronic (over time) or synchronic (in a given instant or moment). In general, most views on the nature of personal identity are concerned with diachronic, numerical identity of persons. To rephrase the initial formulation of this question, we can ask "If a person is numerically the same object throughout time, in virtue of what feature are they numerically the same object throughout time?" Call this the persistence question of personal identity. ${ }^{1}$ Although these are distinct questions, it has been easy to confuse the two since an answer to one is very likely to have implications for what can count as a suitable answer to the other (Olson 2007).

A final matter is distinguishing between the question just asked regarding personal identity and a related, but distinct question. When thinking about what makes someone (loosely, or metaphorically) the same person throughout time in terms of their characteristic, distinctive, most salient properties, we are not simply looking for an answer to either of the previous two questions. We are looking for a different sort of answer altogether. The answer we're looking for will be similar to an answer to the question "Who am I really?" asked after an existential crisis, a traumatic event, a slow change in one's personality, and in other contexts. Call this the characterization question of personal identity, following Schechtman 2017 and Olson and Witt 2018.

This paper is an exploration of the accounts of numerical, diachronic personal identity and personal ontology held by both Kong Zi (孔子) and Derek Parfit, that answers the persistence question. ${ }^{2}$ Kong $\mathrm{Zi}$ and the early $r u$-ists held a conception of the self as dynamic, changing, based entirely on their social roles and relationships with other people. ${ }^{3}$ Derek Parfit, in certain writings, held a view of personal ontology

\footnotetext{
${ }^{1}$ Though this is also called the reidentification question, I follow Olson and Witt 2018 in referring to it as the persistence question, for reasons they outline.

${ }^{2}$ At least, I take it to be the case that each of the answers considered will answer both questions. In considering objections to the hybrid view, I consider an objection related to this nest of questions.

${ }^{3}$ Ames 1991a, 1991b, 1994, 2010, Ames and Rosemont 2016, Bockover 2010a and 2010b, Kim 2011, Hansen 1985, Hall and Ames 1987, Ho 1995, Raphals 2009, Rosemont Jr. 1991, and Yao 1996 either define the Confucian view in these social and relational terms, or use this analysis as a springboard for other philosophical endeavors, while an examination of this view of the self in relation to grief and
} 
requiring we are the thinking parts of human beings, the persistence of which requires Relation R, defined as psychological connectedness and/or continuity (in Parfit 1971, 1984, 1995, and 2012). Of course, the most interesting thesis held by Parfit is that even in the absence of identity, we might care about those future persons distinct from, but related to, our current selves.

In the final section of the paper, I develop a hybrid Confucian-Parfitian Account of both numerical, diachronic personal identity and personal ontology, the hybrid account's insight into the unimportance of personal identity, and explain some potential advantages of such an account. I answer several questions in order to clarify the commitments of the account and consider and respond to some objections to this hybrid account.

In this paper, I will review the answers of both adherents of Confucianism and psychological continuity theory, including Parfit, to these questions. I will argue that in certain specific and important ways, Kong Zi's and Parfit's views are similar. I will give reasons as to why I take this comparative project to be of philosophical value. Finally, I propose a hybrid account that combines the insights of both Kong $\mathrm{Zi}$ and Parfit, and respond to some objections to this account.

\section{EXAMPLES}

In order to flesh out the differences and similarities in the views I consider below, it will behoove us to set out some specific, detailed example cases. This will allow us to see, in application, what these judgments about persons and personal identity amount to for a general psychological continuity theory, Parfit's views about the unimportance of identity, and Kong $\mathrm{Zi}$ and his contemporary interpreters.

\subsection{JOHN'S CASE}

Over his lifetime, John has made many friends, as an outgoing elementary school teacher. John has only been married once, to Martha, and they have one child, Jim. John is a faithful, devout husband and a caring and loving father. The relationships between he and his wife, and he and his son, stay largely the same throughout their lives, despite minor bumps and issues here and there. Martha passes away in her sleep when John is in his 60's. This saddens him deeply, but he still maintains a positive, emotionally rich relationship with his son Jim. In his late 60's, John begins to have concerning memory lapses, and is diagnosed with Alzheimer's disease. At 75, John's Alzheimer's disease has advanced significantly. Now in a care facility, John rarely remembers his wife or son. When Jim comes to visit, John feels fear, anguish, and hostility towards him (or, at times, at John's own fragmented understanding of the situations and persons he finds himself involved with). Jim finds this heartbreaking to see the man that was so loving and kind to him reduced to this state, unable to

memory occurs in Olberding 1997, and Wang 2002 develops a relatively recent analysis of different conceptions of the Confucian view of the self and an argument for a new model. 
remember Jim's childhood, or Martha's laughter, is devastating. Jim also finds his father's behavior especially hard to deal with when John is angry, mean, and aggressive, qualities that were rarely expressed at all prior to the Alzheimer's diagnosis. After several particularly nasty and violent interactions, Jim angrily renounces his father and will have nothing further to do with him beyond paying to maintain his current level of care, despite his disease and John's role in Jim's life as his father. Jim stops visiting John, mentally characterizes John as being a remnant of the prior person he was, and no longer thinks of him as his father.

\subsection{ISABELLA'S CASE}

Isabella has always been described as outgoing. A nursing assistant, she is garrulous and wild, the life of the party in any social situation. As a teenager and through her 20's, Isabella leads a relatively hedonistic, partying lifestyle, and this matches up with her explicit, chosen values - as an example, for her nursing itself is less about caring for others, and more about being a job she sort of fell into. Isabella would describe herself as having many acquaintances, but few friends, and her relationship with her family is complicated. Her relationship with her only living relative, her mother Gladys, is not very good during this period of her life, most of the time there is almost no relationship at all. This is the result of both Isabella's character, as well Gladys'. Isabella is largely cold, dismissive, or even abusive towards her mother, when she is around her. On the other hand, Gladys has been both a doting, caring mother for periods of time, and an absent, uncaring figure in her daughter's life in others. Isabella undergoes a spiritual transformation in her 30s, and changes her life and personality in significant, considerable ways. She stops drinking, using drugs, and partying, and undergoes intense, lengthy personal reflection on her values, how she wants to live, and what makes a life worthwhile. Deciding to live in concert with her newly acquired and chosen values, she begins attending church and recalibrating her understanding of her work as a nursing assistant to be geared toward caring for others who need medical help and attention. Socially, her life changes a great deal. Almost all of her previous friendships, as well as her periodic romantic entanglements, which survived for so long due to comparable values and activities, wither and die. Her relationship with her mother changes in a unilateral way. Isabella is determined to be a good, loving, filial daughter to her mother with regularity, not only on occasion, and so makes every effort to get reacquainted with her mother. For Gladys' part, little changes; she is still sometimes loving and dutiful, and other times absent and disconnected. Isabella's spiritual transformation takes - the remainder of her life is spent developing her virtuous nature, deepening her spiritual relationship, focusing on her career working through different levels of nursing in order to care for the ill and the broken, and trying desperately to be a good, loving daughter. As Isabella gets older, it becomes increasingly difficult for her to even understand the behaviors and motivations of her younger self, including the younger self's values and characteristics, much less evaluate them the same way or endorse them. Until the end of her mother's life, Isabella's 
character remains constant and she maintains as solid a relationship with her mother as the woman allows.

\subsection{MOHSEN'S CASE}

Mohsen's life is almost defined by a series of monogamous romantic relationships. Married four times, and divorced in each case after a serious, years-long relationship, Mohsen is a strict serial monogamist who never lets these relationships have overlapping boundaries. It is not that he doesn't take romantic relationships seriously, but that he is unlucky in love. Each of his partners genuinely enjoy their time with him, but they ultimately come to some irreconcilable difference in the marriage, in value, lifestyle, etc. or they grow apart and decide to end the marriage mutually. Raised only by his father, his turn away from Islam to live a secular life at 18 resulted in his father's disowning him irrevocably. Mohsen never has any children from any of his marriages, other relationships, or through his own individual efforts (e.g., adoption). He has several close friends, but over time most of these fade with one exception. Throughout his life, Mohsen's general character and values remain largely the same as they were at 18 , with some relatively minor changes. He retains a clear memory and psychological character throughout the remainder of his life, suffering from no illnesses or injuries that affect his value, outlook, or memory. At 50, Mohsen passes away suddenly in a freak traffic accident.

\subsection{ZIWEI'S CASE}

Ziwei (紫微) is a filial, respectful child. Her parents, Hong (洪) and Bao (包), have a deep, abiding connection to her and are upright, moral, and loving parents. Throughout her young life, Ziwei is slowly developing into a virtuous young woman. She begins to develop these virtues in a particularly Confucian way - with a focus on ritual and social etiquette, coupled with disciplined attempts to ensure the right emotions and motivations are at the root of the actions she takes, and repetitive training to make these virtues second nature. At 17, Ziwei is tragically injured in a hiking excursion. The brain injuries she suffers result in both severe retrograde and anterograde amnesia. Ziwei does not remember much of the autobiographical details of her past and is unable to form new memories. She remembers her Confucian training, and the importance of roles, relationships, and the attitudes that are supposed to govern them, but does not remember who her mother and father are until they tell her. When they tell her, she tries her hardest to act filially towards them, but she often needs reminding. While her memory of these things is an acute problem, the roots of virtue remain in her character. For her part, when Ziwei is reminded that she attempts to act filially towards her parents and cultivate the appropriate attitudes and motivations, for brief and intermittent stretches of time where she knows her parents. Her parents are deeply grieved in this situation but take their parental roles seriously. During the next several years, they gently remind her of their familial bonds frequently, care for her well-being, and make every effort to treat her brain injury and the conditions associated with it. She is, after 
all, their little girl. After 12 years, much of Ziwei's autobiographical memory returns. Shortly after this, she begins to be able to make new memories. Overjoyed, her parents try to fill her in on the details of the last 12 years with little success. Since Ziwei was unable to form new memories for most of this time period, there is a significant gap in the chain of her memories. She knows, for example, how the family celebrated her $20^{\text {th }}$ birthday, but only abstractly, from the reports of her parents. Despite this difficult circumstance, Ziwei continues to receive treatment to deal with this gap in her memory and continues to develop her virtues more and more thoroughly. For the rest of her parents' lives, she is a filial child who makes them proud.

\section{PERSONAL IDENTITY AND ONTOLOGY IN KONG ZI AND PARFIT}

In this section, I will give a short summary of both the Confucian view of personal identity and Parfit's psychological continuity account of personal identity, as well as his discussion on whether this matters. For each of these two views, I will identify what features, if any, are determinative or constitutive of a person at a given point in time.

\subsection{CONFUCIAN PERSONAL IDENTITY AND ONTOLOGY}

There are several competing models of the Confucian concept of the self or person. ${ }^{4}$ This paper does not try to make any arguments for the superiority or inferiority of one or another of the different models. Instead, this analysis will presume that something like the relational model explained in Ames 1991, 1994 and 2004, and Rosemont Jr. 1991 is correct. To go further, any Confucian model of the self where a person's identity is defined, at a given moment, entirely by their social roles, relations, and their quality, will be consistent with this analysis. Various competing models usually include the centrality of particular, concrete social relations (and their character) in determining the self, even if they conceive of the relations in slightly different, but apparently important, ways. As long as a person's identity at a given moment is entirely constituted by social roles, relations, and their quality, then I believe what I have to say here will not miss the mark. ${ }^{5}$

On this view, what defines a person at a moment are their social roles and relations, and their quality. These roles and the relations necessarily connected to them include those associated with one's family, educational process, profession, and other personal relationships (friends and lovers). Historically, the most important relationships for personal development and constitution were the five relationships: parent-child, ruler-

\footnotetext{
${ }^{4}$ While the terms "self" and "person" are not strictly the same, here I will use them to be relatively interchangeable, and to use these accounts to be focused primarily on giving a numerical, diachronic account of personal identity, personal ontology, and to answer the persistence question.

${ }^{5}$ For example, every model in Ames 1994 with the exception of the Hollow Men would be able to incorporate the essentially social and relational nature of the person in Confucianism. The same is true for every model offered in Wang 2002, with the exception of the Universal Self model, and for every Confucian model offered in Raphals 2009.
} 
subject, serious romantic partners ${ }^{6}$, older sibling-younger sibling, and friends. However, it is plausible to think that the importance of certain relationships has to do with their function, as opposed to their genetic linkage, and contemporary developments of Confucianism often recognize this. ${ }^{7}$ Even Kong $\mathrm{Zi} \mathrm{himself} \mathrm{seems} \mathrm{to} \mathrm{recognize} \mathrm{this} \mathrm{as}$ related to the development of the doctrine of the rectification of names (zheng-ming 正 名) - both Analects 6.25 and 17.11 suggest that a ruler not acting as a ruler is not, properly, labeled a ruler (and so on), and the focus on this functional aspect of social roles is captured in Analects 12.11 as well.

As a personal example, at the time of writing this I occupy the roles of teacher to my students, student to my teachers, advisee to my advisors, brother to my sister, son to my mother, nephew to my aunt, friend to my friends, lover to my lover, etc. In each case, these social relations can (and for their being valuable, must) be described even more particularly, as concrete relationships between specific individuals; that I am a brother to Sally, that I am a teacher to Hannah, that I am a student of Linda, that I am a friend of Adipat, etc. This entire combination of roles I play (teacher, student, son, and so on) and the particular relata are what determines my identity. It is not simply that I am $a$ brother, or $a$ son, or $a$ friend, but that I embody those roles towards specific persons that constitute my identity.

The other important part is the quality of those relations, primarily because in order for me to play a certain role, I have to be playing it minimally well (Ivanhoe 2007). Because of teaching style or personality or other particulars my relationship as a teacher to my students might be of a different quality in different cases (try as I might, it may just be the case that my own style and the learning style of some students are incompatible, and if they are my students then I will, at least, not be a good teacher to them). I have been, at times, a better and worse friend to the same friend, or a better and worse son to the same parent. In each of these cases, the qualities of these relationships play a role in determining my identity. Furthermore, both the existence of particular relationships and their quality are not static, but dependent on attitudes, actions, behaviors, events, and various other features of those people and situations involved. When significant changes in the quality of a relationship, or the dissolution of a relationship entirely occur, these can change who one is, one's personal identity. On this view, when my last surviving parent dies, I will no longer be a son. When, at an earlier stage of my life, I was married and then, later, divorced, I embodied a new

\footnotetext{
${ }^{6}$ Generally, the tradition treats this relationship as the husband-wife relationship, but I do not see any reason to think that persons in homosexual relationships, or those who oppose the formal arrangement of marriage but are heterosexual long-term romantic partners, cannot also have the relevant depth and significance in their romantic relationships that constitute and deeply affect their personhood and their personal development, which is why I've modified the phrasing. I believe this is consistent with how contemporary interpreters of Kong Zi often change the initially phrased relationship from "father-son" to "parent-child" or the "older brother-younger brother" relationship to "elder sibling-younger sibling." However, for sake of ease, all example cases where romantic relationships take on importance involve the formal marriage arrangement, though in those cases, the gender and sexual orientation of the individuals is not always specified.

${ }^{7}$ For example, see the discussion of what counts as a parent in Ivanhoe 2007, footnote 20.
} 
role of husband and then lost that role. On the Confucian relational view of personal identity, when my roles are removed or added, or changed in significant ways, I am literally a different person. A very well-known statement of this comes from an essay by Henry Rosemont Jr., who writes “... for Confucius, I am my roles. Taken collectively, they weave, for each of us, a unique pattern of personal identity, such that if some of my roles change, others will of necessity change also, literally making me a different person," (Rosemont 1991, p. 90)

A key insight here is that the social roles we inhabit and that, for a Confucian, comprise our identity, are social. They affect, and are affected by, others and their views of us. These, in turn, are affected by the roles we inhabit. As a partner to Brittney, I am known by her friends, family, and acquaintances in this way. They recognize me specifically as a person who fulfills that role. The same goes for my familial relations. Sally's friends, in-laws, and husband know me primarily as her older brother. Anne's friends, coworkers, gym acquaintances, and gardening buddies know of me as her son. Paul's wife, his children, and his parents and siblings all conceive of me and know me as his good friend. On a Confucian view, these relationships and the roles I inhabit with respect to them have differing degrees of importance. Returning to the five relationships introduced earlier, in our contemporary lives we see the importance of at least most of these. It is hard to know what to say about the ruler-subject relationship in our modern context. However, other of these important relationships are of considerable significance even 2000 years removed from Kong Zi's discussion of their importance. The role of parents in affecting a child's identity and self-development is now a well-confirmed finding in social and developmental psychology as discussed in Feldman 2018. Parents, for their part, often explain the experience of having children as one of the most rewarding and life-changing experiences on offer, and even after children leave the home the parental role is important for the parent's sense of wellbeing as discussed in White and Edwards 1990. This is true of sibling well being and development as well, as reviewed in Dunn 2002, and there is increasing contemporary philosophical literature on the importance of friendship, reignited by Elizabeth Telfer in Telfer 1970, and continuing forward since as the essays in Badhwar 1993 and Caluori 2013 show. I do not take any of this to establish that Kong Zi's view is correct, but we now have more confirmation than ever of the importance of our social roles and relationships, especially four of the five classical Confucian relationships, with respect to our well-being and our personality formation. This is consistent with and supportive of the Confucian view of the significance of these relationships for our personal identity. As said by a philosopher in another tradition, "A man who is incapable of entering into partnership, or who is so self-sufficing that he has no need to do so, is no part of a state, so that he must be either a lower animal or a god," (Aristotle, Politics, 1253a20 - 30).

Andrea Sauchelli, in Chapter 3 of Sauchelli 2018, has developed a thoughtful and clear schema for disambiguating different ways we might understand this kind of general Confucian claim about the importance of social relationships for personal identity. In terms of Confucian personal identity, Sauchelli gives the following definition. 
Confucian Role Personal Identity: For all times $\mathrm{t}$, person $\mathrm{P}$ at $\mathrm{t}_{1}$ is one and the same person as person $\mathrm{Q}$ at $\mathrm{t}_{2}$ if and only if $\mathrm{P}$ at $\mathrm{t}_{1}$ is constituted by the same social roles $\mathrm{R}$ that constitute $\mathrm{Q}$ at $\mathrm{t}_{2}$, and such roles are those prescribed in the rites of the early Confucian tradition. (Sauchelli 2018, 87)

Sauchelli rightly notes that a very strict reading of this would imply that persons only existed during a brief time and place in history; during the times when and locations where individuals had these roles as described by the early Confucian tradition. For my purposes, I believe that the following tweak of his schema captures the model I'm proposing, allows a broader reading of the applicability of the Confucian insights about important relationships, and fails to imply that most humans that have existed were not persons. The tweak involves two changes. One is the addition of the term 'specific' to modify 'social roles' in the definition, given what I've argued above regarding the importance of specific roles (e.g. that I'm Anne's son, not simply $a$ son) to the Confucian conception of personal identity. The other is to modify the final claim about the early Confucian tradition, so that it is still tight enough to retain the important insights from the tradition about social relationships for our identity, but loose enough to allow both historical and contemporary persons not explicitly in Confucian contexts, or that might not use these exact concepts, to count as persons and to have criteria of personal identity.

Confucian-Inspired Role Personal Identity: For all times t, person $\mathrm{P}$ at $\mathrm{t}_{1}$ is one and the same person as person $\mathrm{Q}$ at $\mathrm{t}_{2}$ if and only if $\mathrm{P}$ at $\mathrm{t}_{1}$ is constituted by the same specific social roles $\mathrm{R}$ that constitute $\mathrm{Q}$ at $\mathrm{t}_{2}$, and such roles are inspired by the works of early Confucians and the rites of the early Confucian tradition.

This modification can also give us an insight into the Confucian account of rolepersonal ontology. On this view, human beings or individuals are not persons, but instead are the kinds of entities that could become persons if other relational conditions occur. Like Parfit, the Confucian account suggests that we are not human beings, but instead, as Ames would have it, "situated, relational human becomings who grow and realize themselves as distinctive persons through a sustained commitment to their always-collaborative, transactional roles with the nexus of family and community," (Ames 1991b, quoted in Sauchelli 2018, p. 85). Further, Sauchelli describes persons as "being constituted by social relations", which implies a distinction between human beings or human individuals and persons. In a way that might be similar to other constitution views about persons, Confucian role-person views might be thought to be similar to other kinds of constitutions views of persons, like that from Baker 2016. However, instead of a body constituting an essentially embodied, first person perspective, a Confucian constitution view might require that persons are constituted by specific social roles and relations, which are themselves dependent upon certain physical and psychological facts about creatures like us.

This is why it is important to recognize that there are a variety of necessary preconditions for social roles and relationships, including the five relationships of the early Confucian tradition. In order for me to be a good parent, I must be capable of love, 
affection, wisdom, righteousness, and many other character traits and virtues. I must have certain psychological capacities to be a parent, or a child, insofar as roles are multidirectional, collaborative things that affect, and are affected by, others. The existence of my body in a persistent vegetative state would be entirely without these capacities or my ability to inhabit those roles. Insofar as role-person accounts require the individuals to be able to inhabit roles and practice specific virtues to inhabit them well, and that require roles that are multidirectional and not simply passive, it will require that we have the capacities to develop virtues and all that this entails, including beliefs, emotions, motivations, and action.

This feature of the Confucian ontology of persons is mutually reinforced by the focus in the early Confucian tradition on moral development and the psychology of human individuals in Confucianism. The importance of the heart-mind (xin 心) for our moral development, as well as our general cognitive capacity of self-reflection, is expressed in any number of written texts in early Confucianism. In order to develop our virtues, we must act the right way, for the right reasons, accompanied by the right kinds of emotions, and ultimately, these acts should be second nature and not require near as much deliberate, conscious effort. There is simply no way to develop virtue as human animals are currently constituted without a great deal of self-reflection, teaching received from others, discipline, and training. Most of these preconditions of the development of virtue will require that we possess fairly robust cognitive and emotional capacities.

This is not unrelated to our relationships. Plausibly, a major part of what it is to be a filial child is to develop the virtue of filial piety (xiao 孝). So not only is our set of psychological and emotional capacities required for the development of our virtues, but they are also required in having full relationships with others. As Michael Puett and Christine Gross-Loh argue in Puett and Gross-Loh 2016, conceiving of oneself as a person with a set of roles is an important part of our moral development, and the development of our moral virtue is an important part of fulfilling those specific roles we inhabit with respect to others in our lives.

\subsection{PARFITIAN PERSONAL IDENTITY AND ONTOLOGY}

Parfit's early view, taken primarily from Parfit 1971 and 1984 is that a person is nothing over and above a collection of physical and psychological particulars at any given moment (including brains and bodies). ${ }^{8}$ Parfit says "The existence of a person, during any period, just consists in the existence of his brain and body, and the thinking of his thoughts, and the doing of his deeds, and the occurrences of many other physical and mental events," (Parfit 1984, p. 275). While a straightforward interpretation regarding identity is that, if a person is defined as above, then any change in any of those qualities should require a revision of identity.

\footnotetext{
${ }^{8}$ In Parfit 1995 he makes the distinction between Identifying Reductionism, Constitutive Reductionism, and Eliminative Reductionism. His own position is one of Constitutive Reductionism, but I do not believe this level of precision is required in making the comparison given in this paper.
} 
However, Parfit argues that this straightforward interpretation given above is not the case. Diachronic personal identity is certainly possible - in cases where relation R holds, it is normally caused, and where there is no branching, we can meaningfully talk about two persons at a temporal distance being numerically identical. Relation $\mathrm{R}$ is defined as "psychological connectedness and/or psychological continuity, with the right kind of cause," (Parfit 1984, p.262). Psychological connectedness is defined as "the holding of particular direct psychological connections." Psychological continuity is defined as "the holding of overlapping chains of strong connectedness" where strong connectedness requires "at least half the number that hold, over every day, in the lives of nearly every actual person," (Parfit 1984, p. 206).

Direct psychological connections between temporally disparate people can include memories of experiences, intentions, values, ambitions, desires - nearly all of the ways in which our psychological facts can be described. Myself today and tomorrow have very strong connectedness - I can remember the experience of typing this sentence, I still value compassion and attempt to cultivate it. All of these are psychological features that can be directly connected to my immediate past or immediate future self. In Parfit 1984, his Reductionist view also requires physical continuity, though the focus even there is the brain. In Parfit 2012, for example, he defines his view of personal identity as follows.

The Narrow, Brain-Based Psychological Criterion States: If some future person would be uniquely psychologically continuous with me as I am now, and this continuity would have its normal cause, enough of the same brain, this person would be me. If some future person would neither be uniquely psychologically continuous with me as I am now, nor have enough of the same brain, this person would not be me. In all other cases, there would be no answer to the question whether some future person would be me. But there would be nothing that we did not know. (Parfit 2012, 6-7)

To translate Parfit's terminology into the schema used earlier, his view of personal identity can be given as follows.

Parfitian Psychological Continuity Personal Identity: For all times t, person $\mathrm{P}$ at $\mathrm{t}_{1}$ is one and the same person as person $\mathrm{Q}$ at $\mathrm{t}_{2}$ if and only if for both $\mathrm{P}$ at $\mathrm{t}_{1}$ and $\mathrm{Q}$ at $\mathrm{t}_{2}$, psychological continuity obtains and is caused normally, by enough of the same brain in each case.

Notice that this definition of personal identity has both a psychological component (the psychological contiguity) as well as a physical component (enough of the same brain). However, in this paper he ends up arguing that, as a matter of personal ontology, we are embodied parts - in other words, "the conscious, thinking, and controlling parts of human beings," (Parfit 2012, p. 14). This is a revision of the views discussed above

${ }^{9}$ The term "branching" used here refers to cases where there might be multiple entities that have psychological continuity with me. For example, if I were to step into Parfit's teletransporter and not one, but two copies of me pop out on Mars, then it seems my psychological continuity has branched to those two replica individuals. Sometimes, instead of the phrase "no branching" added into definitions of psychological continuity, a "no duplicates" clause is added for the same purpose. 
and expressed in Parfit 1984. In the final version of the view, we are some physical particulars with certain mental characteristics, and we are judged to be the same through time on the basis of Relation R, normally caused, with enough of our brain preserved, as discussed above.

A final point regarding Parfit's view is the conclusion he comes to regarding the importance of personal identity. Survival of something similar to my self is important, but personal identity itself is not. This is because, as he writes in Parfit 1984 and Parfit 1995, the facts about our identity are reducible to other facts about physical and psychological continuity. But even in the absence of strict identity conditions I might be able to ascertain, the facts we most care about with still be relevant. If there is some confusion about whether the Replica from the teletransporter will be me, or only a Replica, what is not a matter of confusion is that a person, very similar to me in certain specific ways, will continue to exist and have the kinds of experiences I value, the kinds of psychological . And whether that entity is me or not seems, according to Parfit, a fact about language and not about reality, about concepts and not ontology (Parfit 1995, p. 40-41). Whether I can refer to some future person as being me or not, what is important is that it bear Relation $\mathrm{R}$ to my present self. There is also some striking language that suggests that, while it does not preserve identity, our social relations are among the things that we care about continuing, on Parfit's view. He writes

What we value, in ourselves and others, is not the continued existence of the same particular brains and bodies. What we value are the various relations between ourselves and others, whom and what we love, our ambitions, achievements, commitments, emotions, memories, and several other psychological features. (Parfit 1984, 284, emphasis mine)

\section{APPLICATION OF THE VIEWS TO EXAMPLE CASES}

How do the views of Kong $\mathrm{Zi}$ and Parfit make judgements in the example cases we developed above? In this section, I examine these four cases from both perspectives to see where the accounts coincide in judgment, and where they differ.

First, take John's case. On Parfit's view, John is likely to be the same person for most of his life. It is plausible that, at some point in the development of the Alzheimer's disease, John is no longer the same person due to the lack of psychological continuity with his earlier self. Despite this, for most of his lifetime, his identity is fairly stable. On a Parfitian view, John exists as the same person until far into the Alzheimer's diagnosis. The Confucian view is not so simple. When John gets married, he becomes a different person, and when his wife dies, he becomes a different person. Similarly, when he can no longer play the role of the father, and certainly when his son severs their relationship, he becomes a different person yet again. While there are stretches of time when John's personal identity is the same on both accounts (for example, the long stretch of John's life where he is psychologically continuous with his earlier self and is the husband and father), there are also some key disagreements.

Second, take Isabella's case. Here is another case where the accounts give different judgments at times, and similar judgments at others. While much of Isabella's life has 
a kind of psychological continuity, the spiritual transformation and development suggests a significant break, at least at some point. As she gets older and finds it increasingly difficult to either empathize with or even understand the motivations and values of her younger self, there is a great deal less psychological continuity there. Proponents of psychological continuity theories may object here, but I would argue that cases like this are not about qualitative or characteristic questions of personal identity. It is true that we commonly speak of this same person as having gone through a transformation, but where the psychological differences are so profound, there is reason to think that there is a different person after the transformation, if not immediately then at some further point down the line, due to the widespread change in motivations, values, character traits, and beliefs. It is also true that people who undergo such transformative experiences often say things like "That person (the past version) is dead," or "I am born again" or other phrases that suggest that they take seriously the idea of a separateness and foreignness of their earlier selves. The Confucian view also suggests a kind of change at around the same time. Depending on the specifics of Isabella's relationship with her mother in her youth, we may classify her as either a bad daughter, or as so poor as to not be a daughter at all. At some point after her spiritual transformation and her self-conscious repairing and strengthening her relationship with her mother, the role she inhabits as Gladys' daughter comes to define her life more strongly. The last portion of her life we know about also suggests some different judgments between the views. If Isabella's personal identity changes when she becomes a filial daughter to her mother, then it must also change when her mother passes away, since that relationship and that role are no longer existent. Yet on my construal of the Parfitian view, the life after her transformation is of a piece, hangs together in a unified way, and is the same personal identity despite losing her mother.

Mohsen's case provides another way to cash out the distinct judgments of personal identity generated by the two views. As the case is described, there is good reason to think that Mohsen maintains the same personal identity throughout his life on the psychological continuity view. At no time in his life does he suffer a significant break in psychological continuity, either through disease, injury, or transformative experience. On the other hand, the Confucian account would identify a number of changes to Mohsen's personal identity. He is a son until disowned at 18, and inhabits a specific husband role at some times and the dissolution of that role at others. If we take seriously that these monogamous relationships were not simply transient, shallow engagements, then we should take seriously that Mohsen's personal identity changes each time he is married, and each time he is divorced. We also know that one major relationship, the one with his father, never seems to recover on either side. This provides us yet another way to cash out the different views and the results they might have in different cases.

Our final example case, of Ziwei, is clearer on one view and muddier on the other. In terms of her psychological continuity it is clear that Ziwei's personal identity changes at 17, and again at 29. It is plausible to think that Ziwei was the same person once her memory returns, but that there is a gap in her personal identity during the time she suffers retrograde and anterograde amnesia. On the Parfitian view, this judgment 
can be made despite some slight blurriness in boundaries. The Confucian view is harder to pin down, but I would argue that Ziwei largely remains the same person over the time period of her memory gap, before it, and after it. Her parents take their roles seriously and care for her as parents ought to care for children, and whenever Ziwei is reminded she strives to understand herself as their daughter and act filially towards them, despite having to be reminded of this over and over. This is a tricky case, but distinct from cases where a family member is in a persistent vegetative state or is otherwise unable to perform their familial role in any capacity, since Ziwei can and does act filialy, when she is reminded. If this interpretation is correct, Ziwei's case gives us yet another instance where the two accounts diverge in unexpected ways.

\section{THE SIMILARITIES (INEXACT) BETWEEN THE VIEWS}

Having reviewed both of these theories of the self, it should be immediately obvious that there are a host of differences between the two views. One is concerned with psychological features naturally thought to be internal to oneself, while the other deals with social roles and relationships which by their very nature are extrinsic and relational. One view was advanced several thousand years ago, and the other is less than a hundred years old (in its specifics). There are other differences, but for my own purposes, I am interested in demonstrating how these two radically different views are quite similar in certain respects. ${ }^{10}$

Both the Confucian conception of the self existing through time and Parfit's conception of the self as existing through time involve relations. For Kong $\mathrm{Zi}$ and the Confucians, the relations that matter between selves are social relations and roles. In determining what a person is we must examine the existence and the quality of their identity-constituting relationships, the traditional early Confucian tradition's five relationships. When those relationships change or cease to exist, so too has the person either changed or ceased to exist. For Parfit, the relation between selves of identity (when applicable) and of survival is one of the degree of Relation $\mathrm{R}$, caused in the right way and by enough of the same brain. The greater degree of Relation $\mathrm{R}$ that holds between me and another person (perhaps my future self), the more I have at stake in their condition. At any given moment, I have the strongest Relation R to my current self. But as time passes, the degree of my (current) psychological connectedness to a future self (or far enough past self) becomes lesser and lesser (so too with the degree of psychological continuity). ${ }^{11}$ So in the case of both Confucianism and Parfit, relations

\footnotetext{
${ }^{10}$ While I do not have an explicit, considered view on the appropriate methodology for comparative philosophy, I have found Mou 2010 and 2015 to be helpful in thinking about comparative philosophy methodology. As general descriptions of the enterprise, see Wong 2020 (especially in relation to Chinese - Western comparative philosophy) and Littlejohn 2021. For an argument critical of the common cultural focus in comparative philosophy, see Weber 2013 and 2014.

11 Though I use the term "future self" here, though I do not mean it to be begging the question - clearly if some person is my "self", then it seems they are, by definition, me. I use this language provisionally, and for ease of communicating the right concept, but in cases where personal identity fails to hold, then the provisionally termed "future self" would instead be something like "future person that bears a significant relation to me, but is not identical with me" or something similar. Talk of future or successive
} 
are what matter when we think about personal identity and ontology, though they are not the only thing that matters.

Note also that in each of the views, the person need not essentially be a substance. That is not to say that the person need not be realized or instantiated by something only that this feature is not essential or central to either view of the person. For Confucians, given that the person is simply made up of distinct, particular relationships and social roles, the person simply is a different type of entity than a substance. For Parfit, though the person is a particular physical thing or things, as stated in Parfit 2012 in his description of the embodied parts view, the feature essential to our personal ontology and identity is the activity of thinking, and the thing that matters about our identity or survival (where either do matter) is relational and processual, focusing specifically on sets of physical and psychological features and psychological connections between past, current, and future selves, as well as other relations as he discusses. Notice that, for Parfit, while it doesn't matter if a future entity is me, what matters are these psychological characteristics and relations, and those things require primarily a certain kind of capacity for thought, emotion, and other complex cognitive and affective states. A future being that has none of these things, nor the capacity for them, would certainly not be something worth valuing, even if some part that was previously a thinking part, survived.

Finally, I believe that, in different ways, both views suggest that something like the following thesis: identity through time is actually not what is important about persons existing through time. In fact, I think this is the most important shared feature. For Kong $\mathrm{Zi}$ and his followers, what matters are one's social relations and roles, and their quality - the fact that once I am no longer my father's son or my (ex)wife's husband changes my identity and I am no longer the same person, but if these events are important (and they undoubtedly are) it is not because they require personal identity through time. What matters is the set of relations between my current self and other people. Similarly, for Parfit personal identity not ultimately what matters to the features of personal survival that we care about. We care about our future selves because they share a certain degree of psychological connectedness to us (our current self). What is valuable about these future persons is not that they are identical with us now, but that we share this important relation to some degree or another.

\section{WHY DOES THIS (COMPARISON) MATTER?}

Thus far, this paper has attempted to give accurate accounts of both the Confucian self and Parfit's view of the self. Further, I have shown that in certain ways, Confucianism and Parfit's view are similar. In this section of the paper, I give two distinct reasons why making this comparison is a fruitful and beneficial philosophical exercise.

A major advantage of the comparison argued for in this paper is its novelty. So far as I can tell, no one in the professional literature has made any detailed and explicit

selves seems to me to capture more easily and concisely what is meant here, but I do not intend it to presuppose an answer to the question or carry any important argumentative baggage. 
comparison between Parfit's work on personal identity and the Confucian view of the self. ${ }^{12}$ There are a number of papers that compare the Confucian conception of the self with other Eastern and Western philosophical traditions (such as Bockover 2010a and 2010b, Ho 1995, Raphals 2009, and Yao 1996). Similarly, comparing Parfit to other historical philosophers, especially David Hume and the Buddha, has been a popular scholarly enterprise (such as in Ellis 2000, Gilead 2008, Lowe 1991, Margolis 1988, Stone 1988, and Velleman 2006). ${ }^{13}$ But as far as I have been able to determine, no one has made the kind of extended and detailed comparison between the Confucian view of the self and Parfit's view of the self that occurs in this paper.

A second advantage of this approach comes in using the tools of Parfit to supplement this Confucian view of self, and vice versa. One can model a Confucian response to concern about "future you" in the same way that Parfit models the concern about future selves. In the case of Parfit, what I really care about is that some set of psychological relations (in particular, psychological connectedness, what Parfit refers to as relation R) of a high degree holds between my current and future selves. That is what I care about - that this future person will have a great degree of similarity to me with respect of my memories, desires, values, ambitions, etc (and perhaps have new experiences and engage in new actions related to these psychological states, including values). In the same way, I might (from a Confucian point of view) hold that what I care about in terms of successive selves is that the future person I will become maintain as much of the set of personal relations and roles that I play, to a high degree, and of a high quality (call this relation S). That is what I want for some future self more than identity - that this future person will still be a good brother, student, teacher, mentor, not in general but with regard to concrete, specific individuals that I stand in these relations and roles to and with (and ideally open up new, high quality relationships with others). I am not presupposing that a Confucian that has grown up in this tradition would even feel a need for or attraction to any of this offered above - but for someone, especially a Westerner, that may have come to Confucianism later, this parallel can be very attractive. I think, too, that the insights developed by Kong $\mathrm{Zi}$ and his modern-day interpreters has significant value for Parfit's own project, although I have not developed these insights to any great detail. A realization of the import of social roles and relationships in constituting the self might make a Parfitian view warmer and more human.

In examining the advantages of the comparative project developed in the early part of the paper, it is clear that a kind of hybrid account, incorporating the insights of the psychological continuity theorist, Derek Parfit, and Kong Zi can be philosophically rich, complex, and fruitful. I now turn to developing this account in some more detail.

\footnotetext{
${ }^{12}$ Raphals 2009 mentions Parfit's view at the end of her piece, but she compares this to Daoist views, not Confucian ones, and the comparison is extremely brief.

${ }^{13}$ Parfit himself does this with respect to the Buddha, sometimes comparing and sometimes contrasting, in Parfit 1984 and 1995. Giles 1993 mentions in a footnote Parfit's confusing the Buddha's view as a kind of reductionism, which the later Parfit seems to have noted. In addition, Trycyle magazine posted an article about Tibetan Buddhist monks utilizing Parfit 1984 in their religious and scholarly practices, in "Tibetan Monks Found" 2011.
} 
Though I will develop this account and consider some objections in the final sections of this paper, there are still a number of fruitful, comparative issues and approaches to explore in this general region. ${ }^{14,15}$

\section{THE HYBRID ACCOUNT}

I propose a hybrid account of personal identity and ontology given below.

Hybrid Confucian/Parfitian Account of Diachronic Personal Identity: For all times $\mathrm{t}$, person $\mathrm{P}$ at $\mathrm{t}_{1}$ is one and the same person as person $\mathrm{Q}$ at $\mathrm{t}_{2}$ if and only if

$i$. for both $\mathrm{P}$ at $\mathrm{t}_{1}$ and $\mathrm{Q}$ at $\mathrm{t}_{2}$, psychological continuity obtains and is caused normally, by enough of the same brain in each case, and

ii. $\quad \mathrm{P}$ at $\mathrm{t}_{1}$ is constituted by the same specific social roles $\mathrm{R}$ that constitute $\mathrm{Q}$ at $\mathrm{t}_{2}$, and such roles are inspired by the works of early Confucians and the rites of the early Confucian tradition.

This way of spelling out the hybrid account gives equal weight and importance to both social roles and relations, and psychological continuity, each of which seem to be particularly important to our understanding of our own personal identity and that of others.

This way of spelling out the view on personal identity also comports with the case made above that our Parfitian intuitions about both my psychological traits and capacities distinctive to me are central to my being the same person, and our Confucian intuitions about the roles and relations I inhabit are central to my being the same person.

What about personal ontology? Recall that, for Parfit, we are the thinking parts of human beings. For Kong Zi, we are constituted by social roles and relations. I propose we treat the hybrid view of personal ontology as follows.

Hybrid Confucian/Parfitian Account of Personal Ontology: A person is a complex object constituted both by component a.) a set of social roles and relationships, and component b.) the thinking parts of human animals. These are individually necessary and jointly sufficient for any entity to count as a person.

As with the hybrid view of personal identity, this hybrid view of personal ontology keeps our insights about the importance for both our nature as thinking creatures, and our nature as deeply social creatures, for us to count as persons at all.

\footnotetext{
${ }^{14}$ An additional fertile area might be in applying some other contemporary Western analytic metaphysics literature to the Confucian conception of the self. In conversation, Andrew Russo has proposed that what might be called The Relational Animal Problem, which is structurally similar to Erik Olson's Thinking Animal Problem (Olson 2007), and this could be developed as an interesting puzzle for the Confucian view.

${ }^{15}$ In particular, Eileen Nutting brought to my attention how much the Confucian view might complicate matters of self-definition with respect to others when those others' relations change (e.g. if my sister has a child and becomes a mother, my roles relative to her change and include new items precisely by her other relationships and roles changing).
} 
This view is certainly not straightforward, since it requires us to think of persons as pretty complicated kinds of things - not simply substances, or parts of substances, or sets, but some mereological object that is constituted by both a set of relations and roles and by some substantial parts of a larger object. This is not terribly surprising as far as philosophy, or views on personal identity, go. Clauses about simplicity or parsimony are always ceteris paribus, or "all other things being equal." If I am right about the relative insights and import for both the Confucian view and the Parfitian view as discussed, then a hybrid view will inherit both of these kinds of advantages from its component views. As a view it will discount neither the importance of the psychological dimension of us as persons, nor will it discount the importance of the social dimension of us as persons. Each view on its own leaves some important part of our personhood unrecognized or diminished. The hybrid view does not.

Finally, I think that (as discussed in the previous section), we can spell out a similar insight into what really matters on this hybrid view.

Hybrid Confucian/Parfitian Insight about Personal Identity: Personal identity is not what we care about in terms of our survival (or the survival of something that once was us). What we really care about in terms of survival is both

$i$. The degree to which the future self is similar to us in our psychological relations (relation R), and

ii. The degree to which the future self is similar to us in our social roles and relations, and their quality (relation S).

In this case, the hybrid view helps diminish some of our illusory concerns about personal identity. Whether I am identical in a strict, numerical sense with some future person is less important than that the future person who survives has much of my psychological and evaluative makeup. Similarly, whether I am identical in a strict, numerical sense with some future person is less important than that the future person who survives continues inhabiting the social roles and maintaining the social relations I treasure and treat as constitutive to my personhood. A future person (who bears some intimate, but non-identity preserving relationship to me) who is similar to me in terms of my Relation R and Relation $\mathrm{S}$ will still be a source of joy, happiness, and perhaps even pride for me. A future person who departs much more strongly will be harder for me to appraise or evaluate, whether positively or negatively, depending on the specifics of the situation. If the future person has become a much more knowledgeable, sympathetic, and moral person, and have expanded their relationships and improved their quality, including doing a better job of inhabiting those roles important to me, I am likely to be happy for, though also a bit jealous of, that person. If a future person has significantly deteriorated, has become more immoral and more foolish, more selfish and turned inward, abandoned social roles of import to me and damaged or cut off the specific relationships I once prized so strongly, I am likely to feel sorrow and anger towards that person. But in neither case does this turn on my identity with that person, but with the quality and similarity of their psychological continuity with me as well as the quality and similarity of their relational continuity with me. 
To further flesh out the view, I now turn to some questions about and objections to this proposal. This will allow me to spell out the view in more detail, head off any misinterpretations, and respond to some objections.

\section{QUESTIONS, ANSWERS, OBJECTIONS, AND REPONSES}

Question: What relationships ought to be included in the hybrid view, and what is their relative importance?

Answer: I would argue that at least four of the five relationships (discounting the ruler-subject relationship) from the early Confucian view are the ones most important for this process, though as I said earlier, these should be construed loosely, insofar as the exact duties and obligations of friends to friends, or parents to children, is the subject of some significant cultural and temporal difference. As a reminder, these are the relationships of parent-child, serious romantic partners, elder-singling-younger sibling, and friends. Other relationships can matter, but unless they are functionally more similar to one of the five relationships than any of the actual five relationships had by a person, they will be less important, and have less to contribute, to one's personal identity and ontology. For example, a person who has a very poor home life, where the parents do not care well for the child, neglects their physical and emotional well-being, and often fails to do even formal parenting duties (e.g. sign off on field trips, make sure there is food in the house for the children, attend parent-teacher conferences, etc.) may have someone else, such as a teacher, a religious figure, or even an extended family member play the role of parent much better, and provide the kind of parental relationship that, in terms of its functional import, accurately characterizes the parent relationship as opposed to the child's actual parents. This is not much different than the case of an abandoned child who is adopted, or the case where a close friend plays a role closer to a sibling for an only child, or who plays both roles of friend and older sibling.

In fact, we see this occur in a variety of different ways. A young person who is disowned by their genetic family for whatever reason (occupational choice, religion or irreligion, sexual orientations, gender identity, etc.) often finds other people to inhabit the important parent and sibling-like roles in their lives. It is not uncommon for individuals that comes from broken homes and toxic families to say things like "My friends are my real family," or similar phrases because those individuals did and still do play those important functional roles. If a young child grows up without a mother, an aunt, a family friend, or a grandmother sometimes plays that functional role instead. If a person has a hard time making friends, the may treat a sibling or a romantic partner as they would a close friend, and that person may play both roles for them.

This is not to say that this answer, or my proposed treatment, is not controversial, but only that the importance of these Confucian relationships for our personal and moral developments have strong grounding for their relative significance as compared to other kinds of relationships we might try to pick out. And often, when we do pick out nonstandard relationships for their importance, it is because they fulfill the functional role of one of these Confucian relationships. 
More specifically, the answer must be that this is an empirical matter. The relationships one has as they are growing up are of fundamental importance to one's personal identity, and there is increasing psychological, sociological, and philosophical evidence of the importance of these relationships (parent-child, sibling, romantic partner, and friends), not only in terms of one's overall well-being, but in one's personal development, psychological development, and personal character. I am confident that these relationships, or their functional equivalents in cases where the exact relationship either fails to exist or fails to have a minimal nature, are of the utmost importance for our personal identity and ontology, and I have tried to make that case here.

Question: Isn't the Confucian view basically a narrative account of personal identity? And insofar as the hybrid view includes the Confucian elements, isn't the hybrid view also just basically a narrative account of personal identity?

Answer: Narrative accounts of personal identity hold that a person is who they are not merely because of some minimal set of psychological conditions, but because they tell themselves a story or many related stories about their life, see themselves autobiographically as the central figure or protagonist of their story or stories, and develop in concord with that story or those stories. There are a number of authors identified with narrative accounts, ${ }^{16}$ but the one I will focus on the most is the view developed by Marya Schechtman. ${ }^{17}$ The initial discussion of narrative theories focus on the kind of narrative theory found in Schechtman's earlier work, and the second discussion of narrative theory will focus on Schechtman's later work. Narrative accounts of personal identity all hold something like the following claim, insofar as they attempt to answer the persistence question and not the characterization question.

Narrative Account of Diachronic Personal Identity: For all times $\mathrm{t}$, person $\mathrm{P}$ at $\mathrm{t}_{1}$ is one and the same person as person $\mathrm{Q}$ at $\mathrm{t}_{2}$ if and only if

$i$. for both $\mathrm{P}$ at $\mathrm{t}_{1}$ and $\mathrm{Q}$ at $\mathrm{t}_{2}$, either $\mathrm{P}$ at $\mathrm{t} 1$ has a narrative that identifies $\mathrm{P}$ and $\mathrm{Q}$, or $\mathrm{Q}$ at t2 has a narrative that identifies $\mathrm{P}$ and $\mathrm{Q}$, and

ii. the narrative is identity-constituting, and

iii. the narrative is dispositional (in other words, a person could articulate their narrative if pressed), and

$i v$. the narrative is consistent with the objective facts relevant to the narrative.

Let's unpack some of these claims. Part I of the account is the relevant part of the account that discusses narratives as identifying individuals at different times. This is part of what makes this kind of account focused on the persistence question, and not the characterization question. A person-constituting narrative is a narrative that includes seeing oneself as being in time and/or moving through time, as well as knowledge of one's past and how this is connected to one's present and potentially

\footnotetext{
${ }^{16}$ Other important contributions to the literature on the narrative account of personal identity (or accounts that have been influential in later developments) include Korsgaard 1989, MacIntyre 1981, Rudd 2005 and 2007, and Schroer and Schroer 2014. For some critiques of this family of views, see Strawson 2004 and Olson and Witt 2018.

${ }^{17}$ In particular, the accounts given in Schechtman 1996, 2009, and 2017.
} 
one's future. This identity constituting narrative also requires that we are not merely passive recipients of our story, but active shapers and contributors of the story of our life.

The last two features, iii and iv, of the narrative account, are also called the articulation constraint (iii) and the reality constraint (iv). The articulation constraint requires that one at least be able, in principle, to articulate the major features of one's narrative if asked. Few people see themselves or their lives as explicitly being a story they are the author of, so a narrative account that required that people consciously and explicitly understand their lives as stories would be too high a bar. The articulation constraint only requires that a person be able to discuss their narrative if prompted, with reflection. The reality constraint is meant to ensure that not just any narrative will be fair game. If I tell a grand narrative where I am an alien come to Earth to spy on the Earthlings, this will not be an identity-constituting narrative since it will run afoul of many objective facts: the fact that I have human DNA, was born of a human woman, have never been to outer space, have no connections to any aliens, the uncertainty of aliens existing, or if they do exist, the uncertainty surrounding if they were even able to travel to Earth, etc. This will be true for any number of potential narratives and ensures that the narrative account does not license anyone to tell just any story about themselves and for it to count as true.

It should be clear, given the foregoing discuss of the narrative view of personal identity that there are some similarities. For example, the self-constituting narrative of my life is likely to include other people. My story is not very interesting without my parents, sibling, good friends, and romantic partners. Further, as Schechtman notes, our capacity to develop a narrative and tell stories about ourselves and others is itself the product of social development. No one comes into the world a full-blown narrator of their own life or experience. We learn to tell the story of our self by observing the stories others tell, and by trying on different narrative roles at different times, often explicitly in conjunction with our parents, siblings, and friends. There is also a similarity between roles one might assign or play in a narrative and the roles one might inhabit on the Confucian view. Insofar as a major part of my story is being a son, then it appears that the social role of "son" will be a major part of my narrative. So there is certainly some overlap between the two views given the importance familial and other roles and relationships might play in our narrative.

Despite these similarities, there are important differences. My occupying a role is not always a matter of it relating to a story or narrative, and whether I play the role well has little to do with the story I tell, and much more to do with objective states of affairs such as my attainment of a virtue or lack thereof, or whether my father is dead or not. Further, the reality constraint is too vague to serve the purpose in the Confucian view of the person as the doctrine of the rectification of names. A person's biological father will be their biological father regardless of the story they tell, since it is consistent with the objective facts. Contrast this with the functional account appealed to above regarding the robustness of certain familial and other roles. Finally, on this initial narrative view, I could tell a story consistent with objective facts in such a way that my roles no longer apply to me, without any input from others, and in the Confucian view, 
social roles require the function, acknowledgement, and input of both parties - it is a relational view, not a narrative view of persons.

On Schechtman's later view, the social aspect of narratives is given a greater importance. ${ }^{18}$ This kind of development of a social narrative could be one way to respond to the charge above about narrative's being too individual, and not sufficiently socially grounded. Though her earlier view recognized this feature, the later view makes explicit the importance of others. In fact, the stories others tell about us, on this modified narrative view, can establish our identity even without any narrative given by us.

This social narrative account of personal identity could be specified as follows.

Social Narrative Account of Diachronic Personal Identity: For all times t, person $\mathrm{P}$ at $\mathrm{t}_{1}$ is one and the same person as person $\mathrm{Q}$ at $\mathrm{t}_{2}$ if and only if

$i$. for both $\mathrm{P}$ at $\mathrm{t}_{1}$ and $\mathrm{Q}$ at $\mathrm{t}_{2}$, either $\mathrm{P}$ at $\mathrm{t} 1$ or some other relevantly placed person has a narrative that identifies $\mathrm{P}$ and $\mathrm{Q}$, or $\mathrm{Q}$ at $\mathrm{t} 2$ or some other relevantly placed person has a narrative that identifies $\mathrm{P}$ and $\mathrm{Q}$, and

ii. the narrative is identity-constituting, and

iii. the narrative is dispositional (in other words, a person could articulate their narrative if pressed), and

$i v$. the narrative is consistent with the objective facts relevant to the narrative.

The social narrative account holds that in many cases, our narratives are driven by others and begin before we can develop any narrative, implicit or otherwise. Consider the following story. A child is born too early to poor parents and must be flown to a better equipped and more expensive hospital. The premature child must be kept in a special incubator, be given nourishment with a tube, and must receive significant medical care to ensure the child's survival. The parents may begin this child's narrative with how much of a fighter they are, and how despite their hardships they were determined to live. This then becomes a story repeated to others that care about the family and the child, and these relevantly placed persons accept this account as the beginning of the child's story. Further, once the child is grown, this part of the narrative is incorporated into the child's own story. This story is not uncommon and is very likely to capture what is meant in the social narrative account provided by Schechtman in Schechtman 2017. It also allows the narrative theorist to rebut the complaints raised earlier about the initial narrative accounts not being sufficiently social.

A quick word about the phrase "relevantly placed persons." Not every individual who might tell a narrative about someone can contribute to their narrative. I might tell a fabulous story about the secret lives of the other people in line at the grocery store, but it is implausible to think that I am thereby developing their narrative. On the other hand, the narrative a mother, or other sibling tells about a newborn child, is more likely to count as a development of that individual's narrative. I take the phrase "relevantly

\footnotetext{
${ }^{18}$ A similar view, though different in some respects, is Hilde Lindemann's social constructionist view of persons, as described in Lindemann 2002 and 2014. In fact, Schechtman credits Lindemann's work with making her think more carefully about the social aspects of narrativity relating to personhood.
} 
placed persons" to mean those who are closely linked with an individual, in a familial or personal relationship, that are likely to remain a presence in their lives barring any accidents or emergencies. Schechtman does not use this term, but she makes it clear that not just any narrative told by anyone else will count as an individual narrative the social context and depth of the relations will at least partly determine this.

Now the question initially asked seems even more relevant - doesn't the Confucian view just turn out to be a kind of social narrative account of personal identity? And, insofar as the hybrid view requires this, doesn't the hybrid view turn out to be a kind of social narrative account of personal identity? And if this is true, doesn't that reduce the novelty of this hybrid account?

The similarities between a social narrative account and a Confucian account as outlined do seem even stronger. Now, in addition to the stories told on the narrative account containing important social roles and relations, the process of narrative building becomes more collaborative on this view, in the same way that relationships and relational roles turn out to be collaborative on the Confucian view. The earlier response will not be entirely sufficient to demonstrate the gap between Confucian and narrative accounts if the focus is on social narrative accounts of personal identity.

However, there is a tension in the social narrative account that does not exist in the Confucian role-person account, and the social narrative account is committed to some claims not consistent with the Confucian account of personal identity.

First, it is difficult to see how the social narrative account can maintain the reality constraint. Consider again the description of the premature baby as being inherently a fighter, determined to live. It is possible that this is true to the objective facts in some sense, but a premature child may survive despite their possessing nothing like the trait of a fighter whatsoever, but due to good medical care or the vagaries of chance. Many stories about children begin this way; that ever since the child did some picturesque thing shortly after birth, or because the child kicked in a specific way when the mother was listening to a specific musical artist, it becomes part of some central narrative about the child's overall character, life, and a near-destiny to be achieved. The issue isn't simply that the parent might be wrong, but that the temptation to read back into these past incidents things that confirm something about the child's character later is likely to be indifferent to the objective facts. The Confucian view is not subject to this weakness, since social roles and relations are much thicker concepts that require a great deal more than narrative, whether from oneself or someone else.

Second, the social narrative view developed in Schechtman 2017 holds that narrative accounts of others can be defining for a person despite the ability of a person to develop or construe their own life as a narrative in any way. Drawing on a story told by Hilde Lindemann, Schechtman's work here is focused on classifying severely developmentally disabled family members, people who deteriorate greatly later in life, or even short-lived infants with debilitating illnesses as persons given the way others might constitute their narratives for them, and the role that they play in the narratives of others. For the Confucian view, as I've developed it in this paper, some of these things are simply not possible due to the gap between a social role and relationship's functional requirements and a narrative given by another. It is a terrible tragedy to 
miscarry a child for all family members involved, but the child was never in a position to embrace or reject any familial role at all. Similarly, if we take seriously the rectification of names doctrine, then a human who is simply unable to play any of the previously discussed specified roles or develop any significant social relationships, will simply not turn out to be a person. And this is also true of the hybrid view, insofar as it requires the Confucian social role and relationship conditions.

None of this is an argument that the Confucian view is true and that the social narrative view is false. The reasons throughout this section are given to explain the similarities and differences between the Confucian relational view of personal identity and the narrative view of personal identity. It should be clear that the Confucian view is not simply a narrative view under another name.

Question: Since the hybrid view requires that both the Parfitian condition and the Confucian condition to be met (in the personal identity component, the personal ontology component, and the insight about the unimportance of identity component), what is the relative priority between the conditions? Is each of equal weight? Is one more fundamental than the other?

Answer: In terms of logical priority, each are equally weighted in terms of personal identity, ontology, and the insight about the unimportance of identity and what is important in survival. On the hybrid view of personal identity, ontology, and the insight about what is important in survival, each condition is individually necessary and the conditions together are jointly sufficient.

However, the details are a bit trickier in thinking about personal ontology. While each component might be individually necessary and jointly sufficient, they seem to rely on one another in different ways for their formation and development. It is clear that, in order to inhabit the social roles that contribute to one's personal identity and ontology, one must already be a kind of entity capable of some specific psychological states and characteristics. Without these features, it is hard to see how a person could become a parent or friend to another, or to maintain and contribute to the growth and development of their relationships. In this way, it seems that there is a kind of developmental, if not logical or ontological, priority regarding the idea that we are the thinking parts of human beings.

On the other hand, there is a great deal of evidence that socialization at specific stages is incredibly important in the development of our brain, our personality, and our psychological capacities. When children are not provided adequate socialization at early stages, they lose the capacity to use spoken language, to reason abstractly, and in some cases to empathize with others, all of which are significant characteristics of us as being the thinking parts of human beings. In some cases, it appears that if these capacities are not nourished through socialization, they may be lost forever. This provides us evidence that socialization, including into the five relationships and the appropriate roles inspired by Confucianism, also has some developmental priority over at least some of our capacities as the thinking parts of human beings.

Perhaps, like the hybrid view itself, the best way to discuss the developmental priority between the Confucian component of personal ontology and the Parfitian component of personal ontology is to say that, depending on the specifics, these 
components at different times depend on each other for their full development and expression. In any case, whether one component has developmental priority over the other, the hybrid view asserts that taking each view seriously requires each component to be individually necessary for personal ontology, and jointly sufficient for personal ontology.

Objection: A hybrid view will fail because the two views will give different answers to the same question - in particular, the Parfitian desire to be psychologically continuous through time is at odds with the Confucian view of the importance of psychological change and moral development in coming to inhabit various roles.

Answer: There is some truth to the claim that Parfit and Confucian are aiming at different things in terms of their insight about the unimportance of identity. For Parfit, I seem to want the future person to be similar to me, and so to preserve my psychological continuity, warts and all, whereas the Confucian tradition of moral development and a focus on getting closer and closer to achieving a significant moral good, such as attaining goodness (ren 仁) or becoming a superior person (junzi 君子) ${ }^{19}$, would require that I depart from my current psychological states and attributes. In other words, one view is focused on conservation of previous attributes, while the other is focused on improving oneself and thereby abandoning or growing beyond previous attributes, which seems like trouble for a view combining these two approaches.

While this objection is on to something, I believe that we can understand the hybrid account as an attempt to harmonize some disparities in the individual accounts, and I also take it that the accounts can be construed so as to not be quite as discordant as depicted above. While it is true that Parfit's view of personal identity stresses preservation of current attributes, it is also clear that what is being preserved are specifically things of value in oneself. Nothing in Parfit's view of personal identity or what matters in survival rules out a project of self-improvement, and this is not surprising given Parfit's focus in other work on the importance of moral reasoning. This is attested by the Parfit quote used earlier, that focuses on the importance of a future person is focus on "who and what we love, our ambitions, achievements, and commitments," (Parfit 1984, p. 284). Surely these things could be preserved even in cases of moral improvement and self-development, in the same way that my goal of losing 20 pounds is preserved if I lose 40 pounds, or my goal of being a good basketball player is preserved if I become a great basketball player. In other words, some changes are greater departures than other changes, and it would be consistent with the Parfitian view to allow for these positive changes of personal development.

Similarly, the Confucian tradition's view of moral development is itself broadly conservative. By this I mean that often the focus of moral development is to take something we already innately possess and expand upon it, rather than adopting a new

\footnotetext{
${ }^{19}$ There is a great deal of scholarly disagreement regarding how to translate both ren and junzi into English, and the degree to which there are any precise words or philosophical concepts in English that accurately match the two terms. I take no position on this here, and the English terms used are simply meant as placeholders. The key point, here, is just that becoming a junzi and attaining ren, whatever their exact nature, is something one strives for in the Confucian tradition, and so will require a willingness to change and be improved over time.
} 
outlook or moral focus entirely. If our community and family have done their job, the beginnings of our virtue are already something planted in us and developed throughout our childhood. It is true that moral development requires change, but at least some of this change is in filtering out the superficial, the self-interested, and the lazy from the innate sprouts of goodness (duan 端) already in ourselves, and preserving the good already there. While a Confucian view stresses moral improvement and change consistent with that improvement, the kind of moral improvement the Confucian tradition aims at has a significant element of preservation inherent to it.

All of this is to say that, while an initial appraisal of the two views would suggest they necessarily conflict, I have shown that this picture is not so simple; there is room for improvement and change in a Parfitian view, and the moral improvement consistent with the Confucian view has elements of preservation of existing features in our personhood. The two views do not conflict as neatly or as obviously as this objection claims.

Objection: A hybrid view will fail because the two views are not concerned with the same basic question. Parfit is concerned with both personal ontology and with numerical diachronic identity over time. The Confucian view is not about either of these items - it is about social relationships and the role these play in the story of our life, and sit much more comfortably as being about the characterization question, instead of the persistence question, of personal identity. Since the two positions are not even attempting to answer the same question, a hybrid account will not make sense.

Answer: It is plausible to interpret the Confucian view as answering a different kind of question than the Parfitian view, and some scholars do make clear that this is exactly what they're doing. On the other hand, it is also clear that some scholars take the Confucian position to be a position about personal identity and ontology, and it is appropriate to take these scholars at their word. Sauchelli devotes a chapter to this view alongside psychological continuity views, narrative views, and animalist views, all views concerned with the persistence question. Ames and Rosemont, in different works, compare this view to the Cartesian substance dualist view, which is plausibly interpreted as a view about persistence. Additionally, I have also shown that, despite other ways the Confucian position on persons can be interpreted, it is possible to interpret it as a position on personal identity and an answer to the persistence question. So the hybrid view can use both of these approaches, since both can be seen as targeting the same question about personal identity.

Objections: A hybrid view will fail because the two elements are in tension with one another. On Parfit's view, psychological essentialism is true - persons are essentially psychological entities. This seems in conflict with the Confucian account of persons as essentially relational entities.

Answer: While on the surface there may seem to be a conflict, this is resolved on a more in-depth examination of the views. As I have argued, there are certain preconditions to have thick relations and play the social roles inspired by or identical with those given in the early Confucian tradition. Some of these preconditions explicitly require that humans have certain psychological capacities and properties. 
Here are two such preconditions that require psychological capacities, directly or indirectly.

First, a virtue-oriented account of Confucian ethics requires many of the same features of a western virtue account, including motivation, accompanying emotion, mental and emotional discipline and training to develop and maintain a virtue. Each of these components require that humans have considerable psychological capacities and/or properties. Insofar as these virtues are require to maintain and inhabit certain relationships and roles, especially the five relationships in Confucianism, persons will necessarily have a psychological dimension.

Second, the role of the heart-mind in Confucianism as a faculty of cognition and self-reflection, uniting emotional and cognitive appraisal, gives us reason to think that Confucians understood the importance of the psychological dimension of our lives as persons. Insofar as the heart-mind plays a central role in the moral development of Confucian persons, and a central role in how one inhabits these social roles and maintains these important social relationships, persons will necessarily have a psychological dimension.

If the reasons given here are sound, then there is no reason to think that the hybrid view must fail due to this mis-fit in the characterization of persons.

Objection: The hybrid account falls prey to a dilemma - it is either too vague to answer the persistence question of personal identity (since the underlying ontology of persons will be unclear), or too uninteresting as an answer to the characterization question of personal identity (because all it really says is something like "our psychological states and social roles and relationships all matter greatly for who we are").

Answer: I have explained, in detail, what kind of thing persons would be in this hybrid view in section 7 and in answer to an earlier question in section 8 . I have also explained why there is good reason to think that the Confucian view of personal identity is not about the characterization question, but about the persistence question. Both horns of the dilemma fail.

\section{CONCLUSION}

I have summarized the views of both the early Confucians and Derek Parfit. I have demonstrated that there are a number of interesting similarities between the two views, in spite of the fact that they are separated in time and space by such distance. I have given two distinct reasons that support the philosophical value of this particular comparative project. Finally, I have developed a hybridized theory combining the insights of both Kong Zi and Parfit on personal identity and ontology, explained this theory in detail by way of answering questions, and responded to several objections. The hybrid view is a promising way to think about both personal identity and ontology, and combines several important insights from each of these traditions. While more work needs to be done to develop the view in further detail and consider other objections, the author hopes that this is a sure-footed beginning of that path. 


\section{ACKNOWLEDGEMENTS}

This version of the paper profited from several commenters and philosophers when it was presented at the 2017 Central Session of the American Philosophical Association meeting and at the 2018 Kansas Philosophical Society meeting. Though a number of commenters helped the author develop the argument in the paper in response to criticism and constructive allied comments, the author particularly wishes to acknowledge comments from Dennis Arjo, Andrew Russo, Eileen Nutting, Mihailis Diamantis, David Tostenson, Ben Caplan, Rik Hine, and Bruce Glymour. The author also thanks two anonymous referees from Comparative Philosophy for their constructive criticisms, comments, and thorough feedback. This resulted in a much different, and much improved, version of the paper and the ideas therein.

\section{REFERENCES}

Ames, Roger (1991a), "Reflections on the Confucian Self: A Response to Fingarette", in Mary Bockover (ed.), Rules, Rituals, and Responsibility: Essays Dedicated to Herbert Fingarette (LaSalle Open Court), 103-114.

Ames, Roger (1991b), "The Chinese Conception of Selfhood", in Eliot Deutsch and Ron Bontekoe (eds), A Companion to World Philosophies (Oxford: WileyBlackwell), 148-154.

Ames, Roger (1994), “The Focus Field Self in Classical Confucianism”, in Wimal Dissayanake; Roger Ames; and Thomas Kasulis (eds), Self as Person in Asian Theory and Practice (Albany: SUNY Press), 187-212.

Ames, Roger (2010), "Achieving Personal Identity in Confucian Role Ethics: Tang Junyi on Human Nature as Conduct", Oriens Extremus 49: 143-166.

Ames, Roger and Rosemont, Henry (2016), "Introduction", in Roger Ames and Henry Rosemont (eds), Confucian Role Ethics: A Moral Vision for the $21^{\text {st }}$ Century? (Taipei: National Taiwan University Press), 7-15.

Aristotle (1944), Politics, 1253a20-30, trans. H. Rackham (Cambridge: Harvard University Press).

Badhwar, Neera K. (1993), Friendship: A Philosophical Reader (Ithaca: Cornell University Press). <https://doi.org/10.7591/9781501741104>

Baker, Lynn Rudder (2016), "Making sense of ourselves: Self-narratives and personal identity", Phenomenology and the Cognitive Sciences 15: 7-15. < https://doi.org/ 10.1007/s11097-014-9358-y>

Bockover, Mary (2010a), "Confucianism and Ethics in the Western Philosophical Tradition I: Foundational Concepts", Philosophy Compass 5.4: 307-316. $<$ https://doi. org/10.1111/j.1747-9991.2010.00295.x>

Bockover, Mary (2010b), "Confucianism and Ethics in the Western Philosophical Tradition II: A Comparative Analysis of Personhood", Philosophy Compass 5.4: 317-325. <https://doi.org/10.1111/j.1747-9991.2010.00297.x> 
Caluori, Damian (2013), Thinking about Friendship: Historical and Contemporary Philosophical Perspectives (London: Palgrave Macmillan). < https://doi.org/ 10.1057/9781137003997>

Ellis, Robert (2000), "Parfit and the Buddha: Identity and Identification in Reasons and Persons", Contemporary Buddhism 1.1: 91-106. <https://doi.org/10.1080/1463 9940008573723>

Feldman, Robert (2018), Child Development (New York: Pearson).

Dunn, Judy (2002), "Sibling Relationships", in Peter K. Smith and Craig H. Hart (eds), Blackwell Handbook of Childhood Social Development (Oxford: Blackwell Publishing).

Gilead, Amihud (2008) "A Humean Argument for Personal Identity", Metaphysica 9: 1-16. <https://doi.org/10.1007/s12133-007-0018-3>

Giles, James (1993), "The No-Self Theory: Hume, Buddhism, and Personal Identity", Philosophy East and West 43.2: 175-200. <https://doi.org/10.2307/1399612>

Hall, David and Ames, Roger (1987), Thinking Through Confucius (Albany: SUNY Press).

Hansen, Chad (1985), "Individualism in Chinese Thought", in Donald Munroe (ed.), Individualism and Holism: Studies in Confucian and Taoist Values (Ann Arbor: University of Michigan Press), 35-56.

Ho, David Y. F. (1995), "Selfhood and Identity in Confucianism, Taoism, Buddhism, and Hinduism: Contrasts with the West", Journal for the Theory of Social Behavior 25.2: 115-139. <https://doi.org/10.1111/j.1468-5914.1995.tb00269.x>

Ivanhoe, Philip J. (2007), "Filial Piety as a Virtue", in Rebecca L. Walker and Philip J. Ivanhoe (eds), Working Virtue: Virtue Ethics and Contemporary Problems (Oxford: Oxford UP).

Kim, Sungmoon (2011), "The Anatomy of Confucian Communitarianism: The Confucian Social Self and Its Discontent", The Philosophical Forum 42.2: 111-130. $<$ https://doi.org/10.1111/j.1467-9191.2011.00382.x>

Korsgaard, Christine (1989), "Personal identity and the unity of agency: A Kantian response to Parfit", Philosophy and Public Affairs 18.2: 101-132.

Lowe, E.J. (1991), "Real Selves: Persons as Substantial Kinds", Royal Institute of Philosophy Supplement 29: 87-107. < https://doi.org/10.1017/S1358246100007487>

Lindemann, Hilde (2002), “What Child Is This?”, Hastings Center Report 32.6: 29-38. $<$ https://doi.org/10.2307/3528131>

Lindemann, Hilde (2014), Holding and Letting Go: The Social Practice of Personal Identities (Oxford: Oxford University Press). < https://doi.org/10.1093/acprof:oso/ 9780199754922.001.0001>

Littlejohn, Ronnie (2020), "Comparative Philosophy", in James Feiser and Bradley Dowden (eds), The Internet Encyclopedia of Philosophy. $<$ https://iep.utm.edu/ comparat/>

Lun-Yü《論語》[the Analects], trans. Edward Slingerland (2003), ConfuciusAnalects (Indianapolis: Hackett).

Macintyre, Alasdair (1981), After Virtue: A Study in Moral Theory (Notre Dame: University of Notre Dame Press). 
Margolis, Joseph (1988), "Minds, Selves, and Persons", Topoi 7 (March): 31-45. $<$ https://doi. org/10.1007/BF00776207>

Mou, Bo (2010), "On Constructive-Engagement Strategy of Comparative Philosophy", Comparative Philosophy 1.1: 1-32. <https://doi.org/10.31979/2151-6014(2010). $010104>$

Mou, Bo (2015), "Editor's Postscript: From the Vantage Point of Constructive Engagement Strategy of Comparative Philosophy", Comparative Philosophy 6.2: 58-66. <https://doi.org/10.31979/2151-6014(2015).060207>

Olberding, Amy (1997), "Mourning, Memory, and Identity: A Comparative Study of the Constitution of the Self in Grief", International Philosophical Quarterly 37.1: 29-44. <https://doi.org/10.5840/ipq199737161>

Olson, Erik (2007), What Are We? A Study in Personal Ontology (Oxford: Oxford University Press).

Olson, Erik and Witt, Karsten (2018), "Narrative and Persistence", Canadian Journal of Philosophy 49.3: 419-434. <https://doi.org/10.1080/00455091.2018.1486674>

Parfit, Derek (1971), "Personal Identity", Philosophical Review 80 (January): 3-27. $<$ https://doi.org/10.2307/2184309>

Parfit, Derek (1984), Reasons and Persons (Oxford: Oxford University Press).

Parfit, Derek (1995), “The Unimportance of Identity”, in Henry Harris (ed.), Identity (Oxford: Oxford University Press), 13-45.

Parfit, Derek (2012), "We Are Not Human Beings", Philosophy 87.1: 5-28. <https://doi. org/10.1017/S0031819111000520>

Puett, Michael and Gross-Loh, Christine (2016), The Path: What Chinese Philosophers Can Teach Us About the Good Life (New York: Simon and Schuster).

Raphals, Lisa (2009), "Thirteen Ways of Looking at the Self in Early China", History of Philosophy Quarterly 26.4: 315-336.

Rosemont Jr., Henry (1991), "Rights-Bearing Individuals and Role-Bearing Persons", in Mary Bockover (ed.), Rules, Rituals, and Responsibility: Essays Dedicated to Herbert Fingarette (LaSalle: Open Court), 71-101.

Rudd, Anthony (2005), "Narrative, Expression, and Mental Substance", Inquiry 48.5: 413-435. <https://doi.org/10.1080/00201740500241870>

Rudd, Anthony (2007), "In Defence of Narrative", European Journal of Philosophy 17.1: 60-75. <https://doi.org/10.1111/j.1468-0378.2007.00272.x>

Sauchelli, Andrea (2018), Personal Identity and Applied Ethics: A Historical and Philosophical Introduction (New York: Routledge). $<$ https://doi.org/10.4324/978 1315644288>

Schechtman, Marya (1996), The Constitution of Selves (Ithaca: Cornell University Press). < https://doi.org/10.7591/9781501718380>

Schechtman, Marya (2009), "Getting Our Stories Straight: Self-narrative and Personal Identity", in Debra J.H. Matthews, Hilary Bok, and Peter V. Rabins (eds), Personal Identity and Fractured Selves: Perspectives from Philosophy, Ethics, and Neuroscience (Baltimore: Johns Hopkins University Press). <https://doi.org/ 10.1353/book.3352> 
Schechtman, Marya (2017), Staying Alive: Personal Identity, Practical Concerns, and the Unity of a Life (Oxford: Oxford University Press). <https://DOI:10.1093/acprof: oso/9780199684878.001.0001>

Schroer, Jeanine Weeks and Schroer, Robert (2014), "Getting the story right: a Reductionist narrative account of personal identity", Philosophical Studies 171.3: 445-469. <https://doi.org/10.1007/s11098-014-0278-z>

Stone, Jim (1988), "Parfit and the Buddha: Why There Are No People", Philosophy and Phenomenological Research 48 (March): 519-532. <https://doi.org/10.2307/ 2107477>

Strawson, Galen (2004), “Against Narrativity", Ratio 17.4: 428-452. <https://doi.org/ 10.1111/j.1467-9329.2004.00264.x>

Telfer, Elizabeth (1970), "Friendship", Proceedings of the Aristotelian Society 71.1: 223-241. <https://doi.org/10.1093/aristotelian/71.1.223>

"Tibetan monks found chanting text by Oxford Philosopher" (2011), Trycyle Magazine September 13. $<$ https://tricycle.org/trikedaily/tibetan-monks-found-chanting-textoxford-philosopher/>

Velleman, J. David (2006), "So It Goes", 2006 Amherst Lectures in Philosophy. $<$ http://www.amherstlecture.org/velleman2006/index.html $>$

Wang, Qinjie James (2002), "Genealogical Self and a Confucian Way of Self-Making", International Philosophical Quarterly 42.1: 93-112. <https://doi.org/10.5840/ipq 200242174>

Weber, Ralph (2013), "'How to Compare?' - On the Methodological State of Comparative Philosophy", Philosophy Compass 8.7: 593-603. <https://doi.org/ $10.1111 / \mathrm{phc} 3.12042>$

Weber, Ralph (2014), "Comparative Philosophy and the Tertium: Comparing What with What, and in What Respect?", Dao 13.2: 151-171. <http://doi.org/10.1007/ s11712-014-9368-z>

White, Lynn and Edwards, John (1990), "Emptying the Nest and Parental Well-Being: An Analysis of National Panel Data", American Sociological Review 55.2: 235-242. $<$ https://doi.org/10.2307/2095629>

Wong, David (2020), "Comparative Philosophy: Chinese and Western", in Edward N. Zalta (ed.), The Stanford Encyclopedia of Philosophy (Fall 2020 edition). $<$ https:// plato.stanford.edu/entries/comparphil-chiwes/>

Yao, Xinzhong (1996), "Self-Construction and Identity: The Confucian Self in Relation to Some Western Perceptions", Asian Philosophy 6.3: 179-195. <https:// doi.org/10.1080/09552369608575442> 